\title{
YOGA SEBAGAI JALAN REALISASI KESADARAN DIRI DALAM TEKS TATTWA JNANA
}

\author{
Oleh : I Gusti Made Widya Sena
}

\begin{abstract}
In his life man has two consciousnesses, namely physical awareness and spiritual awareness. Physical awareness is any form of change of mind to know and feel the state of the physical body. A conscious body is a form of representation of various changes in desires that want the body to always be healthy, fit, beautiful and not lack anything. Without us knowing it in the end, physical awareness will bring life to be increasingly tied to the world that is outside us and forget the real world that is within us. This truth is important to realize because knowledge without understanding will be a form of implementation of blind practices. Blindness in question is not blind to the senses, but blind to the psychological aspects by forgetting the true nature of self. For this reason, the right knowledge and understanding and implementation of tattwa teachings, especially regarding Yoga as a Way of Realizing Self Awareness in the Tattwa Jnana Text, is very important to be put forward in daily life towards spiritual awareness and improvement of a harmonious life.

Based on the background above, the authors are interested in raising this paper because previously there had never been any scientific writing or articles related to the theme that the author adopted. In addition, by writing this article, it is hoped that later scientific articles of the same type will increasingly develop and contribute to the world of modern knowledge and health.
\end{abstract}

Key words: Yoga, Self Realization, Tattwa Jnana

\section{PENDAHULUAN}

Dalam kehidupannya manusia memiliki dua kesadaran, yakni kesadaran fisik dan kesadaran spiritual. Kesadaran fisik adalah segala wujud perubahan pikiran untuk mengetahui dan merasakan keadaan tubuh jasmaninya. Tubuh yang disadari adalah bentuk representasi dari berbagai perubahan keinginan yang menginginkan agar tubuh senantiasa berada dalam keadaan sehat, bugar, berparas ayu dan tidak kekurangan suatu apapun. Tanpa kita sadari pada akhirnya kesadaran fisik akan membawa hidup menjadi semakin terikat dengan dunia yang berada di luar kita dan melupakan dunia sesunguhnya yang berada dalam diri kita. 
Saat semakin hari pikiran jenuh dengan memikirkan dan melayani tubuh fisik, maka seseorang perlahan-lahan akan melangkah meninggalkan pikirannya pada tubuh jasmani menuju pada kesadaran spiritual. Kesadaran spiritual bentuknya lebih halus daripada kesadaran fisik. Jika kesadaran fisik membuat seseorang menyadari perubahan pikirannya dalam mengetahui dan merasakan, maka kesadaran spiritual melampaui hal tersebut. Kesadaran spiritual tidak hanya memberikan seseorang pikiran untuk mengetahui dan merasakan, namun juga memahami kenyataan dirinya yang sebenarnya.

Kebenaran inilah yang penting untuk disadari karena pengetahuan tanpa pemahaman akan menjadi bentuk implementasi praktek yang buta. Buta yang dimaksud adalah bukan buta pada indera, melainkan buta pada aspek psikis dengan melupakan hakikat diri yang sebenarnya. Untuk itulah pengetahuan dan pemahaman serta pengimplementasian yang benar dari ajaran tattwa, khususnya mengenai Yoga Sebagai Jalan Realisasi Kesadaran Diri Dalam Teks Tattwa Jnana sangat penting dikedepankan dalam kehidupan seharihari menuju pada kesadaran spiritual dan peningkatan kehidupan yang harmonis.

Berdasarkan latar belakang di atas, penulis tertarik mengangkat tulisan ini karena sebelumnya belum pernah ada tulisan atau artikel ilmiah terkait tema yang penulis angkat. Selain itu dengan menulis artikel ini diharapkan agar nantinya artikel-artikel ilmiah yang sejenis semakin banyak berkembang dan memberikan sumbangan bagi dunia pengetahuan dan kesehatan modern.

\section{PEMBAHASAN}

\subsection{Teks Tattwa Jnana}

Dalam hubungannya dengan tulisan ini kata Tattwa Jnana adalah nama Teks yang terdapat di Bali. Teks tersebut adalah salah satu teks yang tergolong jenis tutur dan penyajiannya berbentuk gancaran atau prosa. Di dalam teks Tattwa Jnana tidak jelas disebutkan penokohan atau dialog yang terjadi antara guru dengan murid itu siapa, tidak seperti teks-teks lain yang bercorak Siwaistik di Bali, yang penokohon dan dialog terjadi secara jelas. Antara Dewa dengan manusia, antara Dewa dengan Dewi dan seterusnya.

Teks ini terdiri dari 8 bab, dengan jumlah sloka sekitar 74 sloka. Teks Tattwa Jnana yang menguraikan ajaran rahasia Siwa ini secara terstruktur tertuang dalam bentuk Bab atau bagian utama. Teks Tattwa Jnana termasuk jenis Tutur dan keadaan sloka Bahasa Jawa Kunanya cukup bagus dengan memiliki jumlah sloka yang cukup banyak. Keunikan dari teks Tattwa Jnana adalah teks tattwa yang hingga kini masih eksis dengan menggunakan bahasa Jawa Kuna tidak seperti kebanyakan teks-teks Tattwa lainnya yang menggunakan bahasa Sanskerta. Kedua, teks Tattwa Jnana disusun dalam bentuk bebas atau prosa, sedangkan yang lainnya berbentuk dialog. Kebanyakan dialog yang terjadi antara Siwa dengan Parwati atau antara Siwa dengan muridnya. Ketiga, teks ini merupakan dasar dari semua tattwa karena isi didalamnya lengkap membahas ajaran teologi, kosmologi dan jalan kelepasan bagi manusia dalam mencapai kesadaran materi- spiritual.

Struktur Teks Tattwa Jnana disusun dalam bentuk bebas atau gancaran prosa 
berisikan pengetahuan mengenai kebenaran dan kelepasan. Pada bab pertama menguraikan tentang cetana, acetana, Parama Siwa Tattwa, Sadasiwa Tattwa dan Atmika Tattwa. Bab ini menjelaskan tentang bagaimana jalan seseorang dapat menghilangkan penderitaannya dengan mengetahui dan memahami pengetahuan dari Teks Tattwa Jnana dengan benar. Bab II hingga bab VII adalah proses penciptaan (kosmologi) yang berada didalam tubuh manusia, sedangkan pada Bab VIII menguraikan tentang jalan mencapai kelepasan melalui jalan prayogasandhi dengan tuntunan samyagjnana yang diperoleh melalui tapa, brata, yoga dan samadhi.

Bab yang slokanya paling sedikit terdapat pada bab VII, sedangkan bab yang paling panjang terdapat pada bab V. Masing-masing bab (bagian utama) dalam teks ini membahas mengenai topik-topik tertentu. Adapun topiktopik itu adalah sebagai berikut:

I. Bab pertama terdiri dari 5 sloka yang membahas tentang "cetana, acetana, Parama Siwa Tattwa, Sadasiwa Tattwa dan Atmika Tattwa. selain itu dalam bab ini juga disebutkan apa yang harus diperhatikan dan dipelajari oleh seseorang yang ingin bebas dari kesengsaraan penjelmaan. Dengan mempelajari dan memahami Sang Hyang Tattwa Jnana dengan baik, maka seseorang akan terbebas dari kesengsaraan.

II. Bab kedua terdiri dari 5 sloka, merupakan kelanjutan dari Bab pertama yang membahas tentang Bhatara Dharma mengembangkan cetananya. Disini disebutkan mengenai citta, satwam, rajah dan tamah. Pradhana tattwa hadir dalam bab ini yang menghasilkan pradhanapurusa.

III. Bab ketiga terdiri dari 4 sloka juga menguraikan tentang asal-usul dan sifatsifat ahangkara yang melahirkan Dasa Indriya, Panca Tan Matra dan Panca Maha Bhuta. Adapun ahangkara terbagi menjadi tiga bagian, yakni ahangkara si waikrta adalah buddi sattwa, ahangkara si taijasa adalah buddhi rajah dan ahangkara si bhutadi adalah buddhi tamah.

IV. Bab ini terdiri dari 7 sloka, membahas tentang pengertian dan pembagian sapta loka, sapta patala, perbedaan peranannya dengan wiswa, serta pengertian satwam, rajah dan tamah. Sapta loka terdiri dari satya loka bertempat di paling atas, kemudian berturut-turut di bawahnya adalah maha loka, jana loka, tapa loka, swar loka, bhuwar loka dan bhur loka. Sapta Patala terdiri dari patala, witala, nitala, mahatala, sutala, tala-tala dan rasa tala.

V. Bab kelima terdiri dari 24 sloka, menguraikan tentang punarbhawanya sang hyang atma, serta sifat-sifat dan cirri-cirinya. Pada bab ini diceritakan bagaimana atma mendapatkan buah karma semasa hidupnya di dunia serta pelaksanaan ajaran prayogasandhi sebagai obat dalam melepaskan diri dari kesengsaraan yang diderita oleh atma.

VI. Bab VI ini terdiri dari 11 sloka membahas mengenai perwujudan Sang Hyang Atma dalam badan manusia, atma mendapat pengaruh dari Panca Maha Bhuta, hubungannya dengan Sad Rasa, Panca 
Tan Matra, sapta Bhuana, Sapta Parwata, Sapta Arnawa, Sapta Dwipa dan sepuluh nadi. Pada bab ini disebutkan bahwa atma dilahirkan dalam wujud sebagai manusia, lahir ke bumi, tinggal dan mendiami badan jasmani, menyusup dalam sad rasa yang merupakan sari-sari dari Panca Maha Bhuta yaitu tanah, air, cahaya, angin dan udara.

VII. Bab VII ini terdiri dari 3 sloka membahas tentang pengertian Wayu, Panca Atma, Dasa Indriya, tempat Sang Hyang Tri Purusa didalam badan, tempat Panca Rsi, Dewa Rsi, Sapta Rsi, Dewata dan Widyadhara-widyadhari, Gandharwagandharwi. Dalam bab ini juga membahas bagaimana Sang Hyang Atma terbagi menjadi 5 bagian, yang terdiri dari Atma, Paramatma, Antaratma, Suksmatma dan Niratma menjadi satu kesatuan didalam pikiran manusia.

VIII. Bab kedelapan terdiri dari 15 sloka, membahas tentang pengertian brata, tapa, yoga dan Samadhi. Dalam bab ini juga masih sekilas membahas pradhana tattwa, ambek (pikiran) dan prayogasandhi itu tidak dapat dilaksanakan tanpa tuntunan samyagjnana (pengetahuan yang benar). Itu mengapa dengan pemahaman dan pengimplementasian yang benar dalam mengetahui prayogasandhi sangat diutamakan dalam mencapai alam pembebasan.

Teks ini mengatakan bahwa semua yang ada berasal dari yang "kesadaran dan tanpa kesadaran", yang disebut cetana dan acetana. cetana dan acetana. Cetana adalah Śiwatattwa dan acetana adalah māyā tattwa. Sama- sama kecil dan halūsnya. Māyātattwa lebih rendah dari Śiwa tattwa. Māyā tattwa tidak memiliki cetana, tidak memiliki jñāna, hanya lupa tidak memiliki kesadaran. Ketiadaan sebagai badannya, kosong bebas tiada yang merintangi. Lupa tidak ingat apapun, demikianlah sifatsifat Māyā tattwa. sedangkan sifat Śiwa tattwa adalah kebalikannya, memiliki sifat-sifat kesadaran, jernih dan bercahaya. Yang disebut Śiwatattwa ada tiga macam, yaitu: Paramaśiwa tattwa, Sadāśiwa tattwa, Ātmika tattwa. Dari cetana ini dipertemukanlah dengan pradhāna tattwa hingga lahirlah citta, Ketika bertemunya pradhāna dengan purușa itulah melahirkan citta dan guṇa. Citta adalah wujud kasarnya purușa. Guṇa adalah hasil. Pradhāna tattwa yang diberi kesadaran oleh puruṣa. Adapun Guṇa itu tiga jenisnya yang berbeda-beda, yaitu: sattwa, rajah, dan tamah. Itulah yang disebut Tri Guna yang dipakai sebagai guna (kualitas) oleh Citta.

Demikian ajaran jnana yang tertuang dalam teks ini menguraikan anatomi niskala yang harus diketahui oleh para yogi. Anatomi niskala inilah ajaran pengetahuan yang sesungguhnya dan harus terus digali melalui kecerdasan yang tinggi, sehingga dengan mengetahui pengetahuan yang tinggi ini, para yogi dapat menyatu dengan Siwa yang disebut dengan moksa. Moksa dalam Teks Tattwa Jnana merupakan sebuah kondisi dimana orang dapat mencapaiNya melalui disiplin diri, melepaskan diri dari ikatan duniawi dan nafsu keinginan serta mengetahui hakikat Brahman. Jika diuraikan maka seseorang harus mempelajari dan mempraktekkan asana, pranayama, pratyahara, dharana, dhyana, tarka dan Samadhi. 


\subsection{Yoga Sebagai Jalan Realisasi Diri Dalam Teks Tattwa Jnana}

Untuk bebas dari ikatan karma maka seseorang harus melalui kesadaran akan kesatuan dan keselarasan dengan seluruh alam termasuk dengan manusia itu sendiri. Pengaruh maya sangat kuat dalam mengikat karma manusia di dunia. Sattwa, rajah dan tamah yang melekat pada alam pikiran (citta) itulah yang menyebabkan ātmā menjelma berulang-ulang. Namun jika sattwa terang bercahaya besar pada alam pikiran itulah yang menyebabkan àtmā mencapai kelepasan (kamokșan). Bila sattwa bertemu dengan rajah, terang-bercahaya citta itu. Itulah yang menyebabkan ātmā datang di sorga, karena sattwa ia ingin berbuat baik, maka rajahlah yang melaksanakan sampai berhasil semua kehendak sattwa itu.

Demikianlah hakekat kebenaran rajah itu ikut seta berbadan sorga, terbawa oleh sattwa. Bila sattwa bertemu dengan rajah tamah, terang bercahaya citta itu dan itulah menyebabkan àtmā itu menjadi manusia, karena sattwa, rajah dan tamah tidak sejalan kehendaknya. Ciri sattwa adalah berbuat yang baik, melaksanakan dharma, berderma, berbuat jasa. Ciri rajah adalah keras dan marah. Ciri tamah adalah sembunyi, enggan makan dan tidur. Sattwa, rajah dan tamah tidak sejalan namun bertentangan. Itulah sebabnya tidak ada prilaku yang baik ataupun buruk yang terjadi hanya karena salah satu yang berjalan. Kelahiran dan penjelmaan berulang-ulang senada dengan apa yang tersirat didalam teks Tattwa Jnana 18 berikut ini:

Mapa kari yukti nikang sattwa, rajah, tamah, an patmah tmahan, maputera ring swarga naraka, manasā triyak. Sugyan mangkana linga sang para, nda nakan pih, ikang ahangkāra tiga prabhedanya, maparantirikang buddhi, hana buddhi sattwa, hana buddhi rajah, hana buddhi tamah, ya ta tumutakan sakapti ning yoninya, pinaka janmanya wruh pwa sang mpunatattwa, an mangkana kramanya, ya ta matangnyan kawruhana, ikang yoni mangdadyakên kamokșan, lawan swarga, nguniweh ikang janma waluy-waluy, nihan kramanya kengêtakna.

(Tattwa Jnana, 18)

\section{Terjemahan:}

Bagaimanakah sesungguhnya sattwa, rajah, tamah itu ? yang menjelma berkali-kali Berputar-putar di antara sorga dan neraka, manusia dan binatang. Mustahil, demikian kata orang kebanyakan. Bukan demikian. Ahangkāra itu ada tiga macamnya, yaitu : yang tempatnya pada buddhi : ada buddhi sattwa, ada buddhi rajah, ada buddhi tamah. Itulah yang mengikuti apa yang diingini oleh yoninya. Sebagai penjelmaannya. Sadarlah orang arif akan hal tattwa, bahwa demikian keadaannya. Itulah sebabnya hendaknya diketahui bahwa yoni itu yang menyebabkan kamokṣan, sorga, demikian pula penjelmaan yang berulang-ulang. Demikianlah halnya hendaklah diingat.

Metode atau jalan mencapai Tuhan dalam teks Tattwa Jnana adalah melalui jalan prayogasandhi. Yoga memiliki arti "penyatuan" yang mengarah kepada penyatuan jiwa individual dengan Brahman. Seperti yang tersirat pada teks Tattwa Jnana sloka 25 berikut ini: 
Ndah ya tiki dana sanghyang tattwa jñāna, apan pinintonakên ri kita kamung para, ya ta matangnyan, ya ta marya maka jātinya mangkanekang rāt, yang wruha kita rumase, rumêngö, rasa sanghyang tattwa jñanna, yapwan enakatamwanira sanghyang tattwa jñāna, de nikang rāt, yeka sangkaning tuturnya, gumawayakna rasaning prayogasaidhi, maka suluh tang samyagjñāna, maka bhūmyabarata, tapa, yoga, samādhiyeka ning ātmā sangsāra.

(Tattwa Jnana, 25)

\section{Terjemahan:}

Maka inilah tujuan Sanghyang Tattwa jñāna, ditunjukan pada anda sekalian yang menyebabkan akan berakhir kebentuk asalnya, demikianlah dunia ini. Apabila anda tahu akan merasakan, mendengar intisari (rasa) Sanghyang Tattwajñāna. Apabila dengan baik dapat memahami Sanghyang Tattwajñāna, oleh masyarakat yaitu dari kesadarannya untuk melaksanakan prayogasañdhi, dengan penerangan samyagjñāna, dengan berdasarkan brata, tapa, yoga, samādhi, itulah obat dari ātmā yang sengsara.

Yoga berasal dari akar kata "yuj", yang artinya menghubungkan, dan yoga itu sendiri merupakan pengendalian aktivitas pikiran dan merupakan penyatuan dengan alam dan dengan Tuhan. Yoga merupakan salah satu dari enam ajaran dalam Filsafat Hindu, yang menitikberatkan pada aktivitas meditasi, dimana seseorang memusatkan seluruh pikiran untuk mengontrol panca indera dan tubuhnya secara keseluruhan dan bersamaan. Karena yoga sebagai pengendalian gerakan pikiran (Citta Vrtti Nirodhah)
Yoga merupakan media untuk menyatukan diri dengan Tuhan melalui jalan gerakan fisik, kesadaran akan pernafasan dan meditasi. Yoga bukan saja untuk menyatukan diri dengan Tuhan (Parahyangan) melainkan juga menyatukan manusia dengan alam (Palemahan) dan sesama (Pawongan). Konsep Tri Hita Karana sebagai kearifan lokal sangat tepat dalam menjembatani hubungan antara yoga dengan konsep spiritual di Bali.

Didalam teks Tattwa Jnana 21 disebutkan jika kurang yoga maka penjelmaan Sang Hyang Atma akan terjadi secara terus menerus seperti dijelaskan sebagai berikut :

Buddhi tamah akan diceritakan berikut ini. Tidak resan pada apa yang dimakan. Ia merasa kenyang dengan secabik sayur, sekepal nasi seteguk air, seteguk tuak, puaslah hatinya, dengan itu, kelahiran bhūtayakșa tamah yang demikian. Tempat tinggalnya di desa, sebagai dewanya logam, tinggal pada linga, pratima, arca pujaan. Bila ada buddhi tamah, memilih apa yang dimakan, bukan emas yang diinginkannya, yaitu paling tidak ditolaknya, apa saja yang gemerlapan tidak diinginkannya, tidak masuk dihatinya. Namun bila ia menemukan makanan, sejuklah hatinya. Kelahiran Bhūtadêngên tamah yang demikian. Tempat tinggalnya di wangle (?), sebagai dewanya kayu banaspati (beringin). Bila buddhi tamah, sama saja apa yang dimakan, tidak memilih apa yang diinginkannya, semua daging yang dipandang orang haram dimakannya saja, asalkan membuat kenyang, katanya, kelahiran bhūtakāla tamah yang demikian. 
Tempat tinggalnya ialah di kuburan, perbatasan, permakaman, simpang emapt. Bila ada budhhi tamah, mau saja ia makan yang tidak enak yang menyebabkan kemudian gelisah resah, ke barat ke timur, tidak mengenal letih. Kemudian sadarlah ia tertipu barang orang, yang menyebabkan ia menjadi masgul dan lesu namun masih tergila-gila. Dipasangnya juga telinganya, bila mendengar ada makanan. Kelahiran bhūtapiśāca tamah yang demikian. Tempat tinggalnya di angkasa, berjalan-jalan, tidak bergerak. Itulah yang disebut orang kebanyakan "sasabawuh". Demikian keadaan buddhi tamah, madhyama, uttama. Sattwa, rajah dan tamah itulah yang menyebabkan ātmā menjelma berkali-kali. Demikianlah keadaan hendaknya diingat. Apabila bertemu bhūtayakșa dengan dewaṛ̦i saptaṛși, pañcaṛși, tripuruṣa, terang bercahaya besar budhhi itu, itulah yang menyebabkan ātmā mencapai kamokṣan. Adapun bhūtadêngên hanya daitya bertemu dengan daitya, widyādhara, dewatā, terang bercahaya besar buddhi itu, itulah yang menyebabkan ātmā mencapai sorga. Kemudian apabila bhūtakāla bertemu dengan rākṣasa, gandharwa, terang bercahaya buddhi itu, itulah yang menyebabkan ātmā menjelma sebagai manusia. Namun apabila bhūtapiśāca bertemu dengan rākșasa, terang bercahaya benar buddhi itu, itulah yang menyebabkan ātmā itu jauh ke neraka. Kemudian apabila hanya bhūtapiśāca, terang bercahaya besar buddhi itu, itulah yang menyebabkan àtmā menjelma sebagai binatang. Inilah hendaknya diingat juga, yang menyebabkan Sanghyang ātmā berbeda- beda, semakin besar, Sanghyang Tripurușa. Tripuruṣa ialah Bhațāra Brahma, Wiṣṇu, İ́swara. Ialah yang merupakan sattwa yang utama. Ialah sattwa yang terutama. Bila ia kurang hati-hati, kurang yoga, pañcaṛși kurang yoga saptaṛși jadinya. Saptaṛși kurang yoga dewaṛsi jadinya. Dewaṛ̦i kurang yoga dewatā jadinya. Dewatā kurang yoga widyādhara jadinya. Widyādhara kurang yoga akan menjadi gandharwa. Gandharwa kurang yoga akan menjadi dānawa. Dānawa kurang yoga akan menjadi daitya. Daitya kurang yoga akan menjadi rākșasa. Rākṣasa kurang yoga akan menjadi bhūtadêngên. Bhūtadêngên kurang yoga akan menajdi bhūtakāla. Bhūtakāla kurang yoga akan menjadi bhūtapiśāca. Bhūtapiśāca kurang yoga akan menjadi manusia. Manusia tidak memiliki jñanasakti, sebab tempat penimbunan baik dan buruk, menyamai dewatā. Di dalam manuṣa sakti dikatakan melebihi cara dewatā juga. Manusia yang kurang yoga akan menjadi binatang. Binatang ada lima jenisnya, yaitu : paśu (binatang) yang lahir di desa. Mrga ialah binatang yang lahir di hutan. Pakși ialah segala yang terbang. Mina ialah yang lahir di air. Pipīlikā adalah nama binatang yang berjalan-jalan dengan dadanya. Tidak dapat diketahui nama lagi. Itu yang disebut segala makhluk hidup. Sarișpa ialah yang menjalankan dadanya, Sthāwara ialah yang bergerak di tempatnya, berjalan yang layu menebar. Demikianlah penjelmaannya sanghyang ātmā bila manusia kurang hatihati dan kurang yoga.

Ada pun pradhānatattwa merupakan badan sanghyang ātmā atau, dalam diri manusia, 
ambêk (pikiran) namanya. Ambêk itulah dijadikan wujud sanghyang ātmā pada diri manusia, sebagai ātmā yang berada dalam badan. Anga namanya badan itu,ambêk namanya pradhānatattwa itu. Ambêk dan badan itu disebut angapradhāna pada diri manusia, yang menyebabkan ambêk menyatu dengan apa yang disebut baik dan buruk. Dari ambêk lahirnya baik dan buruk itu, suka dan duka yang dirasakan oleh manusia. Dari ambêk juga timbulnya rasa menikmati obyek kenikmatan melalui daśendriya, berpintukan daśamārga. Ambêk pun meresap ke dalam dunia kenikmatan. Maka sadarlah sang nipunatattwa (orang yang mengetahui hakekat) akan hal itu. Itulah sebabnya maka daśendriya hendaknya ditarik dari obyek keinginan, kembalikan ke dalam ambêk. Ambêk dikembalikan ke dalam pramāṇa, pramāṇa, dikembalikan ke dalam dharmawiśeșa, dharmawiśeșa ke dalam anta wiśeșa, anta wiśeșa dikembalikan ke dalam anantawiśeșa.

Untuk mengembalikan ke anantawiśeșa perlu melakukan prayogasandhi yang diketahui oleh sang yogiśwara. prayogasandhi itu tidak dapat dilaksanakan tanpa tuntunan samyagjñāna (pengetahuan yang benar). Dengan menggunakanan samyagjñāna maka kawisesaannya (keutamaannya) akan diperoleh. Samyagjñāna itu tidak akan diproleh tanpa bhūmi brata (brata di dunia), tapa, yoga dan samādhi. Kesimpulannya dengan bhūmi brata, tapa, yoga dan samādhi sebagai penuntun (suluh) samyagjñāna, dengan perantaraan prayogasañdhi maka seseorang dapat mewujudkan keutamaan ketuhanan, seperti halnya panah yang dipanahkan sesudah memakai busur akan tepat menuju sasarannya.
Prayogasandhi itu dipandang sebagai panah yang tajam dan runcing. Samyagjñāna dipandang sebagai sayapnya, brata, tapa, yoga dan samādhi dipandang sebgagai daṇḍacāpa (panah daṇ̦a). Semuanya itu meluncurkan prayogasañdhi, bersayapnya samyagjñāna, berbusurkan brata, tapa, yoga dan samādhi. Seperti yang tersirat didalam teks Tattwa Jnana sloka 62 berikut ini:

Inilah prayogasandhi, hendaknya diingat. Prayogasañdhi artinya usaha, yaitu : āsana, prāṇāyāma, pratyāhāra, dhāraṇa, dhyāna, tarka, samādhi. Ikatan semua itu sandhi namanya. Hendaknya cetana saja dibiarkan bersinar menyatu, tegak berdiri tanpa mendua, tenang tanpa lenyap, berbadankan catur dhyāna. Yang disebut catur dhyāna ialah tișthan, bhojan, gacchan dan suptan. Tișțhan artinya bhațārā duduk. Bhojan artinya bhațāāā makan. Gacchan artinya bhațārā pergi. Suptan artinya bhațāāā tidur. Kesimpulannya hendaknya bhațārālah yang diingat dalam segala gerak prilaku orang, sebab yang disebut ingat itu adalah perwujudan bhațārā dalam diri yang nyata ini. Dan ada āsana namanya, yaitu padmāsana, wajrāsana, payangkāsana, swastikāsana, widyāsana, daṇụsana. Demikianlah āsana itu, enam jenisnya, namun hakekatnya satu. Itulah hendaknya dipilih oleh orang yang melatih Prayogasañdhi ketika ia hendak duduk. Setelah duduk, ia menyimpan sanghyang urip, usahakanlah supaya menyatu. Setelah sanghyang urip tersimpan, maka ia melakukan praṇāyāma. Ada wāyu (angin) pembasuh yaitu : recaka, pūraka dan kumbhaka. Recaka ialah keluarkan nafas 
lebih dahulu dari mulut. Demikianlah dan usahakan (?) kunci, tahan sekuat tenaga mengunci. Kemudian hiruplah nafas kembali, yang demikian pūraka namanya. Kumbhaka ialah : setelah menghirup nafas, tahan, kunci kuat kuat. Setelah dapat menguncinya hembuskan keluar melalui netradwāra (pintu mata). Bila belum terlatih, keluarkanlah melalui hidung, pelan-pelan jangan tergesa-gesa (?). Tujuh diwasa (saat ?) menguncinya. Bila payah hentikanlah. Sungguhsungguhlah menguncinya, menyatu. Tujuan pranāyāma itu ialah menjadikan rajah dan tamas teduh ke dalam terangnya sattwa dan jangan hanya pada jasmani saja. Dan ada lagi kunci lain dari itu, yaitu tidak menghembuskan nafas keluar. Pendeknya diam saja. Mari kita ceritrakan recaka, kumbhaka lebih dahulu, agar diusahakan kunci rahasya. Pendeknya cetana saja dibiarkan bercahaya terang, dudukkan pada kadalipuṣpa (bunga pisang) . Bila sudah ditetapkan di sana, akan terdengar hati-hati yang teduh, terus sampai ke antahkarāṇa. Itulah yg disebut memuja prāṇasanddhilajāâti, yaitu pūjājāti sembuh hyang sūkșma. Bila sudah demikian maka melaksanakan samādhi itu sudah tajam, benar-benar hilanglah wāyu (nafas) yang kasar, mati lenyap ke asalnya, sebab ātmā itu tak dapat dipikirkan. Demikianlah jalan kuñci rahasia itu.

Didalam teks Tattwa Jnana juga disebutkan pratyahara yoga, dhyana yoga, pranamayoga, dharana yoga, tarka yoga. Pratyahara yoga adalah penarikan semua indriya dari obyek kenikmatannya, lalu kemudian di kumpulkan dan dipusatkan dalam citta, buddhi dan manah. Batin yang tidak mendua, tidak berubah-rubah, jernih, tetap teguh tanpa ditutupi apa-apa, hal ini disebut dhyāna yoga. Pranamayoga adalah menutup semua pintu seperti hidung, mulut, telinga. Dengan menarik nafas terlebih dahulu lalu keluarkan melalui ubun-ubun. Bila belum bisa nafas dibiarkan berlalu disitu, dapat dikeluarkan melalui hidung. Keluarkan nafas secara perlahan-lahan.

Omkāra śabda bertempat didalam hati. Itulah yang menghilangkan apa yang didengar pada waktu melaksanakan yoga, dalam keadaan demikian Bhațārā Śiwa berwujud śiwātma. Inilah yang disebut dengan dhāraṇa yoga. Sanghyang Paramārtha adalah hakekat yang tertinggi, bedanya dengan angkasa ialah tidak ada suara padanya. Demikianlah hakekat paramārtha itu, bedanya dengan awang-awang. Persamaannya ialah sama-sama jernih. Yang demikian itulah tarkayoga namanya.

Jika dalam meditasinya seseorang seperti bertemu dengan gandharwa, ada seperti widyādhara yang menyambut sang yogiśswara pada waktu beryoga dan ada lagi yang berwujud dewatā membawa singasana emas dan menyuruh sang ṛ̦i supaya duduk dan melihat r̦sii datang, memuja dengan hujan bunga, atau membawa harta kekayaan dan mengajar sang yogīśwara waktu beryoga, maka yang demikian itu, sattwa upasarga yang ditemukan oleh sang yogî́wara.

Jika seseorang atau yogīswara telah menemukan samādhi sebagai kesadaran spritual, maka ia akan memiliki kāṣțaiśwaryan dalam kehidupan ini. Seperti yang tersirat dalam teks Tattwa Jnana sloka 67-72 berikut ini: 
Yapwan mangkana lwir nikang samādhi kapangguh de sang yogīśwara, wyakti sira makadrebya kāṣteśwaryan mangke ring sakāla, apa sinangguh kāṣteśwaryan ngaranya anunggung sampun manêmwakên yogìswara, hana kasiddhyan ngaranya, lwirnya nihan, animā, laghimā, mahimā, prāpti, prākāmya, ìsitwa, waśitwa, yatrakāmā-wasāyitwa, animā ngaranya, ikāwak sang yogīśwara, ganal tambayan, wakasan-alit, sūkșma, ya ta matangnyan sang yogīswara wênang sapanira, tan katahan sira dening gunung watu, wênang ta sirāsiluruping lêmah, tan hana madhana keśwaryanira, yeka sinangguh animā ngaranya.

(Tattwa Jnana, 67)

\section{Terjemahan:}

Bila demikian hanya samādhi yang ditemui oleh sang yogīśwara, maka nyata-nyata ia memiliki kāṣtaiśwaryan dalam kenyataan ini. Apa yang disebut kāṣțaiśwaryan itu ? Dialah yang sudah mendapatkan yogīśwara. Ada kasiddhyan namanya, yaitu : animā, laghimā, mahimā, prāpti, prākāmya, īśstwa, waśitwa, yatrakāmāwasāyitwa, animā ialah : badan sang yogīśwara pada mulanya kasar, akhirnya menjadi kecil, halus. Itulah sebabnya sang yogīśwara dapat berpergian kemana saja, tidak terhalang ia oleh gunung batu, dapat masuk kedalam tanah. Tidak ada yang menyamai kaiśwaryannya. Itulah yang disebut animā.

Laghimā ngaranya, ikāwak sang yogiśwara, abyetambyan, wkasanadhangan kadi kapuk, ya ta matangnyan sang yogīśwara ambaramārga anampak gagana, ajalāntara, wênang manampak wye, yeka laghimā ngaranya.

(Tattwa Jnana, 68)

\section{Terjemahan:}

Laghimā ialah : badan sang yogīśwara pada mulanya berat kemudian ringan seperti kapuk. Itulah sebabnya sang yogīśwara jalannya adalah udara, menapak ruang angkasa, ajalāntara, wênang manampak wye, yeka laghimā ngaranya.

Mahima ngaranya, mara sira ring deśāntara, punyā sinêmbah sira kinabaktyan sira, sapanira tan ginulanggulang, yeka sinangguh mahimā ngaranya. Prāpti ngaranya, tka sakahurunirekang wastu, tanulihingangel yeka prāpti ngaranya. Prākāmya ngaranya wnang ta sirāgawe rūpa nira dadyanom dadyatuha, dadyalanang, dadyawadon, wênang ta sira masuking jñ̄̄na irikang rāt kabeh, yeka sinangguh prākāmya ngaranya.

(Tattwa Jnana, 69)

\section{Terjemahan:}

Mahimā ialah : Ia pergi ke darah lain, dipuja, disembah, dihormati, sejauh perjalanannya tidak dipermainkan orang. Itulah yang disebut mahimā. Prāpti ialah : apa saja keinginannya pada suatu dapat terpenuhi, mendapatkannya tiada dengan susah payah. Itulah prāpti namanya. Prākāmya ialah : Ia dapat menjadikan wajahnya muda, tua, menjadi laki-laki, menjadi perempuan, dapat memasukkan batinnya pada semua orang. Itulah yang disebut prākamya. 
Iśtwā ngaranya, mara sira maring swarga kahyangan, pinüjā inascana sira dening watêk dewatā, ri kahyangan ira, tan hana dewatā sumikareng sira apan bhațārā mahulun hana ringawak sang yogiśwara, yeka sinangguh iśitwā ngaranya.

(Tattwa Jnana, 70)

\section{Terjemahan:}

Iśitwa ialah : Ia pergi ke sorga, ke khayangan. Ia di puja, dihormati oleh para dewatā semua, atau ia dapat menundukkan para dewatā di khayangannya. Tidak ada dewatā yang merintangi ia, karena bhațārā yang menjadi junjungan itu ada dalam diri sang yogīśwara. Itulah yang disebut Íśitwa.

Waśitwā ngaranya, tan hana wênang langghana nira, tan kahalangan sira ring sakeccha nira, yeka sinangguh waśitwa ngaranya.

(Tattwa Jnana, 71)

\section{Terjemahan:}

Waśitwa ialah : tidak ada orang dapat melawan segala kata-katanya, tiada rintangan aka apa diinginkannya. Itulah yang disebut waśitwa.

Yatrakāmāwasāyitwa ngaranya, wênang sira tumimbah ikang watêk dewatā nguśa tmahanya, tan hana wênang langghana sawuwus nira, tan kahalangan, sawalen, wnang ta sira sumawa dewatā, mangdadnya manușa, yang langghana ri sira, yeka sinangguh yatrakāmāwasāyitwa.

(Tattwa Jnana, 72)

\section{Terjemahan:}

Yatrakāmāwasāyitwa ialah : ia dapat memerintahkan para dewatā, kuasa jadinya, tidak ada yang dapat melawan segala kata-katanya, tiada rintangan, dapat mengutuk para dewatā menjadi manusia bila menantang dia. Itulah yang disebut yatra kāmāwasāyitwa.

Demikianlah yang disebut kāṣṭaiśwaryan, tanda orang yang telah mendapatkan yogawiśeșa, karena tidak nanti pada waktu mati yang disebut kelepasan, namun sekarang juga bisa tampak tanda-tandanya. Disebut mendapatkan kelepasan karena tidak dapat disembunyikan dia yang telah nyata mendapatkan yogawiśeșa. Tidak ada karma yang melekat pada sang yogīíwara, karena telah dibakarnya semua itu waktu berada di alam yoga. Itulah sebabnya tidak ada karma yang melekat pada sang yogíśwara. Endapan rajah dan tamah dibakarnya dahulu waktu berada di alam yoga, endapan sattwa merasuki sang yogīśwara. Karena buah buddhi sattwa yang melepaskan sang yogīśwara dari buah buddhi rajah. Dan buah buddhi sattwa dijadikan badan oleh sang yogīśwara, kemudian dinikmati oleh sang yogīśwara. Jika habis endapan sattwa dinikmati oleh sang yogīśwara, maka pada saat itulah berpisah pañca mahā bhutā, dan akan kembali pada tempatnya masing-masing.

Seseorang yang memiliki kesadaran dan kearifan, yang telah mengetahui hakekat prayogasandhi, apalagi mereka yang menyiapkan tapa, brata, yoga dan samādhi dan yang mengembangkan jñāna (batinnya) dapat masuk ke dalam yogawiśeșa. Demikianlah sang yogīśwara sadar, kembali menyatu badannya dengan hakekat Bhatāāā Paramaśiwa, dengan 
sarana prayogasandhi, dengan dasar brata, tapa, yoga dan samādhi. Teks Tattwa Jnana menganjurkan agar brata, tapa, yoga, samādhi terus dilakukan guna mencapai kesadaran spritual. Pada waktu bersamādhi sang ātmā wiśeșa memuja Sanghyang İśwara. Perenungan yang mendalam melalui meditasi pada Sang Hyang Iswara ini perlu dilakukan dalam melepaskan keterikatan karma yang berulangulang hingga pada akhirnya dapat mencapai kesadaran atman, sebagai realita tertinggi.

\section{SIMPULAN}

Teks Tattwa Jnana adalah salah satu teks yang tergolong jenis tutur dan penyajiannya berbentuk gancaran atau prosa. Teks ini terdiri dari 8 bab, dengan jumlah 74 sloka. Teks Tattwa Jnana yang menguraikan ajaran rahasia Siwa ini secara terstruktur tertuang dalam bentuk Bab atau bagian utama. Pada bab pertama menguraikan tentang cetana, acetana, Parama Siwa Tattwa, Sadasiwa Tattwa dan Atmika Tattwa. Bab ini menjelaskan tentang bagaimana jalan seseorang dapat menghilangkan penderitaannya dengan mengetahui dan memahami pengetahuan dari Teks Tattwa Jnana dengan benar. Bab II hingga bab VII adalah proses penciptaan (kosmologi) yang berada didalam tubuh manusia, sedangkan pada Bab VIII menguraikan tentang jalan mencapai kelepasan melalui jalan prayogasandhi dengan tuntunan samyagjnana yang diperoleh melalui tapa, brata, yoga dan samadhi. Bab yang slokanya paling sedikit terdapat pada bab VII, sedangkan bab yang paling panjang terdapat pada bab V.

Teks Tattwa Jnana termasuk jenis Tutur dan keadaan sloka Bahasa Jawa Kunanya cukup bagus dengan memiliki jumlah sloka yang cukup banyak. Keunikan dari teks Tattwa Jnana adalah teks tattwa yang hingga kini masih eksis dengan menggunakan bahasa Jawa Kuna tidak seperti kebanyakan teks-teks Tattwa lainnya yang menggunakan bahasa Sanskerta. Kedua, teks Tattwa Jnana disusun dalam bentuk bebas atau prosa, sedangkan yang lainnya berbentuk dialog. Kebanyakan dialog yang terjadi antara Siwa dengan Parwati atau antara Siwa dengan muridnya. Ketiga, teks ini merupakan dasar dari semua tattwa karena isi didalamnya lengkap membahas ajaran teologi, kosmologi dan jalan kelepasan bagi manusia dalam mencapai kesadaran materi- spiritual.

\section{DAFTAR PUSTAKA}

Azwar, Saifudin. 2004. Metode Penelitian. Yogyakarta: Pustaka belajar.

Sena, I Gusti Made Widya. 2015. Konsep Teologi Agama Hindu Dalam Teks Tattwa Jnana . IHDN Denpasar.

Tagel, I Dewa Putu. Teologi Hindu Dalam Teks Siwagama Dan Implementasinya Di Kota Denpasar. 2015. Disertasi. Program Pascasarjana IHDN Denpasar

Tim Penyusun.1998. Tattwa Jnana. Surabaya: Paramita.

Teeuw, A, 1984. Sastra dan Ilmu Sastra, Pengantar Teori Sastra. Jakarta: Pustaka Jaya. 